\title{
Sibling Experiences of Adverse Childhood Experiences: A Scoping Review.
}

Ben Donagh - Doctoral Researcher - Corresponding author University of Birmingham, UK. BXD946@student.bham.ac.uk

Professor Julie Taylor - Professor of Child Protection and Director of Research University of Birmingham, UK.

Muna al Mushaikni - Doctoral Researcher University of Birmingham, UK.

Professor Caroline Bradbury-Jones - Professor of Gender Based Violence \& Health University of Birmingham, UK.

\begin{abstract}
Adverse childhood experiences (ACEs) are traumatic events during childhood known to affect health and wellbeing across the life-span. The purpose of this scoping review was to understand what we currently know about the experiences of siblings living with ACEs. Sibling relationships are unique, and for some the most enduring we experience. These relationships can be categorised by love and warmth, however, can also be a point of escalating conflict and problems. This scoping review was conducted following Arksey and O’Malley's (2005) methodological framework, complemented by the PAGER framework (Bradbury-Jones et al, 2021), offering a structured approach to the review's analysis and reporting through presenting the Patterns, Advances, Gaps, and Evidence for practice and Research. In June 2020 we searched 12 databases, with 11,469 results. Articles were screened for eligibility by the review team leaving a total of 148 articles meeting the inclusion criteria. Findings highlighted five main patterns: (1) the influence of birth order (older siblings shielding younger); (2) the influence of sibling relationships (lack of research exploring sibling types outside of biological siblings); (3) identifying siblings experiencing
\end{abstract}


ACEs (when one sibling experiences adversity, it is likely that their other siblings also do, or experience vicariously); (4) siblings who cause harm (siblings harming other siblings is often normalised and minimised, especially by parents); (5) focus on individual ACEs (the majority of studies explore ACEs in isolation). Our findings suggest future research would benefit from an increase in theoretical understanding and exploration of different types of sibling relationships (full, step, half). 


\section{Sibling Experiences of Adverse Childhood Experiences: A Scoping Review.}

\section{Background/ Context:}

Adverse childhood experiences (ACEs), of which there are most commonly 10, are traumatic events during childhood that are known to affect health and wellbeing across the life-span (Crouch et al., 2019; Felitti et al., 1998; Hargreaves et al., 2017; Leban \& Gibson, 2019). There is not one fully agreed list of ACEs (Finkelhor, 2020). Depending on a study's methodological approach, definitions and the number of ACEs measured can vary, with the first study conducted in the 1990s measuring only seven ACEs (Felitti et al., 1998; Manyema \& Richter, 2019). The second wave of studies updated this list to a total of ten within three categories, which now appear to be the most commonly used:

- abuse (emotional abuse, physical abuse, sexual abuse),

- neglect (emotional neglect, physical neglect)

- and household dysfunction (domestic violence and abuse, substance abuse, mental illness, parental separation or divorce, incarceration) (Hargreaves et al., 2017; Manyema \& Richter, 2019).

There does however continue to be variation between studies; a 2016 National Survey of Children's Health in the United States chose to only measure nine ACEs, two of which were racial/ethnic mistreatment and economic hardship (Crouch et al., 2019). There are ongoing debates around which ACEs should be measured and the implications or limitations of studies when they do not include stressors that effect a child's wellbeing; an example of this being poverty (Hughes \& Tucker, 2018).

Variations amongst studies are also seen with their approach to measuring ACEs. Blum, Li, \& Naranjo-Rivera, (2019) identified the four most commonly used approaches: (1) 
Cumulative ACEs scores, (2) Weighting individual ACEs, (3) Weighting ACEs by subgroup, and (4) ACEs typology.

(1) Cumulative ACEs score is when the number of unique ACEs are added together and no consideration is given to frequency, duration or intensity (Blum, $\mathrm{Li}, \&$ Naranjo-Rivera, 2019).

(2) Weighting individual ACEs involves giving consideration to particular characteristics of each ACE and these being weighted accordingly; events that are more recent, severe or frequent are weighted higher (Blum, Li, \& Naranjo-Rivera, 2019).

(3) Weighting ACEs by subgroup consists of ACEs being grouped into categories and each category being weighted rather than the individual ACE, creating a hierarchy of severity (Blum, Li, \& Naranjo-Rivera, 2019).

(4) ACEs typology involves clustering ACEs together when assessing against them, such as 'low ACEs', ‘household dysfunction', ‘emotional ACEs', and 'high/multiple ACEs' (Blum, Li, \& Naranjo-Rivera, 2019).

Felitti et al., (1998) used the ACEs typology approach, asking a total of eight questions within the category of childhood abuse and nine questions within the category of household dysfunction. Respondents were defined as exposed to a category if they responded "yes" to one or more of the questions in that category (Felitti et al., 1998).

The prevalence of ACEs has been discussed at length, with the original ACE study finding one in four adults to report three or more ACEs (Felitti et al., 1998). Later studies have found them to be somewhat more prevalent within particular populations such as children in care and children within the welfare system (Bramlett \& Radel, 2014; Hargreaves et al., 2017). Correlations have also been identified with regards to the number of ACEs individuals are 
likely to encounter; Duke et al (2010) assert that individuals who report at least one ACE are likely to report experiencing others, with Baglivio \& Epps (2016) strengthening this by finding $67 \%$ of their participants who were exposed to one ACE had also been exposed to four or more (Leban \& Gibson, 2019).

Studies have found ACEs impact a child's social and emotional development as well as causing poor health across their life course, such as having a greater risk of poor physical or mental health, chronic disease, and cancer (Blum, Li \& Naranjo-Rivera, 2019; Choi, Wang, \& Jackson, 2019; Crouch et al., 2019). Associations have also been found between ACEs and health harming behaviours such as drug use and smoking at an early age alongside developing depression and anxiety, and also premature death (Brown et al., 2009; Chapman et al., 2004; Crouch et al., 2019; Dube et al., 2003). Impact has also been documented around exposure disrupting healthy brain development in childhood (Crouch et al., 2019; Garner, 2013; Shonkoff et al., 2012; Shonkoff, Boyce, \& McEwen, 2009).

The identification of ACE exposure can inform early interventions, thus potentially mitigating the long-term impact they can have, however limitations have been found with this process (Crouch et al., 2019). The lack of consistency in the number of ACEs measured and methodological approaches make it more difficult to create a consistent understanding between studies (Hargreaves et al., 2017; Manyema \& Richter, 2019). In addition to this, most commonly the study of ACEs is undertaken retrospectively, relying on the recall of adults around exposure in childhood meaning potential information biases can be a major threat (Crouch et al., 2019; Anda et al., 2006; Felitti et al., 1998). Exploring ACEs contemporaneously with children and young people, rather than retrospectively as adults, has 
been found to improve the ability of services and caregivers to mitigate the exposure and impact, reducing the likelihood of poor outcomes (Crouch et al, 2019).

\section{Sibling relationships:}

Compared to other family relationships, sibling relationships are argued to be understudied despite being the longest-lasting relationship is most people's lives (Gilligan, Stocker \& Conger, 2020). As many as $85-90 \%$ of children are reported to grow up with at least one brother or sister (Milevsky, 2011; Tippett \& Wolke, 2015). Siblings may or may not be blood related, and the definition of siblings can vary between studies. Kiselica and Morrill-Richards (2007 p.149) provide a useful outline of the different types of sibling relationships. These relationships include: "biological siblings, (share both parents), half-siblings (one parent in common), step-siblings (connected through marriage of parents), adoptive siblings, foster siblings (joined through a common guardian), or fictive siblings (united by emotional bond)”. Others (Bass et al, 2006) also recognise children who had been living together in the same family and had assumed the role of siblings for two or more years.

The sibling relationship is unique, and for some can be one of the most enduring relationship we have, starting at birth and continuing until death. Siblings can provide an important source of support and play a vital role in an individual's wellbeing (Davies 2015; Edwards et al 2006 Exley, 2021; Yucel \& Yuan, 2015). These relationships can be categorised by love and warmth, providing security and the opportunity to develop social abilities and self-identity (Davies 2015; Edwards et al 2006). However, sibling relationships can also be a point of escalating conflict and problems (Buist, Deković, \& Prinzie, 2013). Some sibling relationships may be ingrained with rivalry and conflict, with distance being introduced when they leave the parental home. 
To our knowledge, there have been no scoping reviews of the literature on sibling experiences of ACEs. Our scoping review helps to address this gap. We aim to provide valuable insight that could help statutory bodies, service providers and policy makers develop effective intervention and/or prevention approaches, as well as inform the direction of future research around this topic.

\section{Methods:}

This scoping review was conducted following Arksey and O’Malley's (2005) methodological framework of a five-stage approach: identifying the research question; searching for relevant studies; selecting studies; charting data; and collating, summarising, and reporting the results. This approach has been complemented by the PAGER framework (Bradbury-Jones et al, 2021) which offers a structured approach to the analysis and reporting of scoping reviews through presenting the Patterns, Advances, Gaps, and Evidence for practice and Research within the included articles. Articles within this scoping review were identified following the Preferred Reporting Items for Systematic Reviews and MetaAnalyses extension for Scoping Reviews (Moher et al, 2009; Tricco et al., 2018). This comprehensive approach enabled an exploration across multiple disciplines to answer one key research question: What do we currently know about the experiences of siblings when living with Adverse Childhood Experiences (ACEs)? (Peters et al., 2015).

\section{Search Strategy:}

The following combination of terms were used to identify articles by searching the abstract and title: adolescen* OR child* OR teen* OR "young people" OR "young person" AND sibling* OR brother* OR sister* OR step-brother* OR step-sister* OR half-brother* OR half-sister* OR twin* AND "adverse childhood experience*" OR "childhood trauma" OR 
trauma* OR abuse* OR "physical abuse" OR assault* OR attack* OR "emotional abuse" OR "sexual abuse” OR rape* OR groom* OR "physical neglect” OR neglect* OR "emotional neglect” OR “mental illness" OR “mental health" OR "incarcerated relative*” OR prison* OR incarcerat* OR arrest* OR "domestic violence" OR "domestic abuse" OR "marital violence" OR "intimate partner violence" OR "gender-based violence" OR "substance abuse" OR "substance misuse" OR drug* OR alcohol* OR addict* OR divorc*.

Following multiple initial searches to finalise terms and databases, final searches were conducted in June 2020 producing 11,469 articles from 12 databases: Consumer Health Database, CINAHL, EMBASE, Healthcare Administration Database, Medline, PILOTS, PubMed, ProQuest Central, PsychInfo, Web of Science, Applied Social Sciences Index \& Abstracts (ASSIA) and the International Bibliography of the Social Sciences. Inclusion criteria for eligible articles were:

1. Considered siblings in the context of an ACE.

2. Adversity took place between birth and 18 .

3. Written in English.

4. Published 2005-2019

5. Peer-reviewed, empirical articles only

No limit was set for the age of participants so as to include both studies which collect data from children and young people and also those which collect from adults retrospectively.

Duplicates were removed, leaving 6,331 articles to be screened by title and abstract. 4,350 articles were excluded by title and a further 1,645 by abstract, leaving 336 articles for full text reviews. Initially, we planned to include articles from 1995-2019 to capture all articles published since the first ACEs study was conducted, however this strategy identified more 
results than we had the resources to review. The timescale was reduced by 10 years, meaning the final agreed timescale was 2005-2019 and a further 84 articles were excluded at this stage. Ten percent of the remaining 252 were reviewed by abstract and title by two reviewers (insert later and by full text by another reviewer (insert later). Any discrepancies were discussed and resolved. A total of 104 articles were excluded following full-text reviews, leaving 148 articles within this scoping review. See PRISMAScR Diagram in Figure 1.

A literature matrix was created, extracting the following data from each of the 148 included articles: author, year, title, country of origin, research method, theoretical input, sample size, sample demographic, type of ACE, whether the term 'ACE' was used, sibling type, whether siblings were the primary focus, and an overview of the article's key findings. Analysis was completed using the PAGER Framework, starting with the identification of patterns (Bradbury-Jones et al, 2021). Patterns were identified in two stages; initially within each individual ACE category before being identified across multiple ACE categories. We created spider diagrams for each ACE as a visual tool to organise the data in a logical way. This process then enabled the analysis of data to identify Advances, Gaps, and Evidence for practice and Research.

\section{Findings:}

Descriptive summary:

Articles were located worldwide ( 25 countries) with the vast majority conducted in the USA (75 articles, 51\%); a significant jump from the second highest being the United Kingdom (UK) at 17 articles (11\%). Given the geographical reach, by default diversity will have been a consideration within some articles, based upon where they were conducted. However, the explicit discussion of diversity appears to be lacking. Within our review we have identified 
medRxiv preprint doi: https://doi.org/10.1101/2022.02.04.22270452; this version posted February 6, 2022. The copyright holder for this preprint (which was not certified by peer review) is the author/funder, who has granted medRxiv a license to display the preprint in perpetuity.

It is made available under a CC-BY-NC-ND 4.0 International license .

that age and gender commonly appear to have been considered within many articles, however other protected characteristics are not so commonly discussed.

Figure 1 - PRISMAScR Diagram

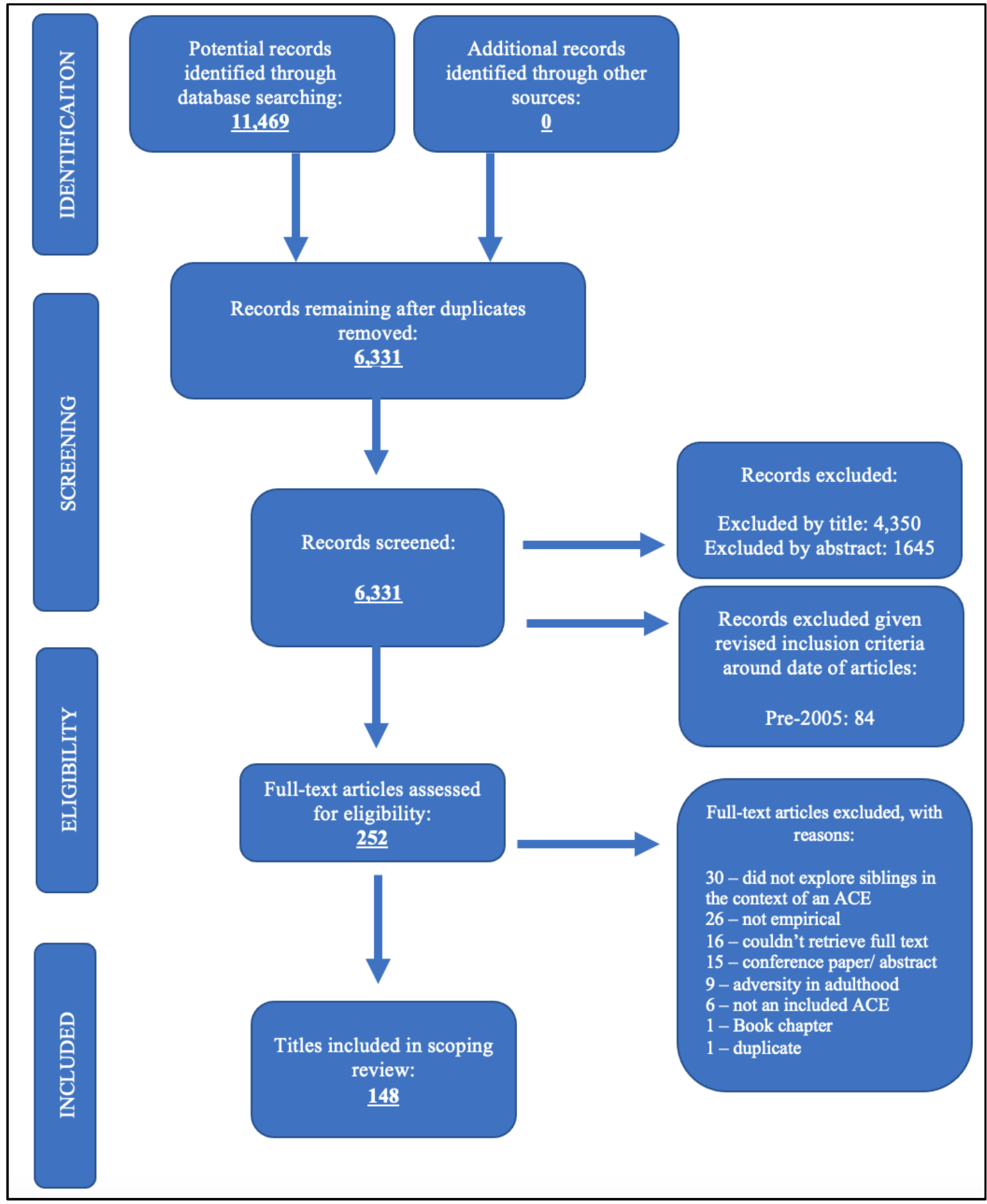

The articles were clustered by childhood adversity type: physical abuse (27\%; 40/148), 
medRxiv preprint doi: https://doi.org/10.1101/2022.02.04.22270452; this version posted February 6, 2022. The copyright holder for this preprint (which was not certified by peer review) is the author/funder, who has granted medRxiv a license to display the preprint in perpetuity.

It is made available under a CC-BY-NC-ND 4.0 International license .

emotional abuse $(1 \% ; 2 / 148)$, sexual abuse $(20 \% ; 30 / 148)$, neglect $(1 \% ; 2 / 148)$, mental illness $(6 \% ; 8 / 148)$, divorce $(11 \% ; 16 / 148)$, incarceration $(4 \% ; 6 / 148)$, substance abuse $(7 \%$; 10/148), domestic violence $(9 \% ; 14 / 148)$, ACE $(8 \%, 12 / 148)$, maltreatment $(6 \% ; 8 / 148)$; see Figure 2. Disparities between the terminology and definitions used meant decisions were made regarding which ACE category some articles were grouped within. Articles which explored broad categories of 'trauma' or 'child abuse' (Foroughe \& Muller, 2014; Heins et al, 2011; Lo, Lau \& Yu, 2017) or explored multiple but not all of the ACEs included in this review (Hindle, 2007; Wolfe, 2016) were included in the ACE grouping. Also, the small number of articles exploring neglect $(\mathrm{n}=2)$ did not differentiate between physical and emotional neglect, so these have been grouped together within the overarching category of 'neglect'. A category of 'maltreatment' was introduced to the review following a number of articles $(n=8)$ which used this term to cover a combination of abuse and neglect.

\section{Figure 2 - ACE Categories}

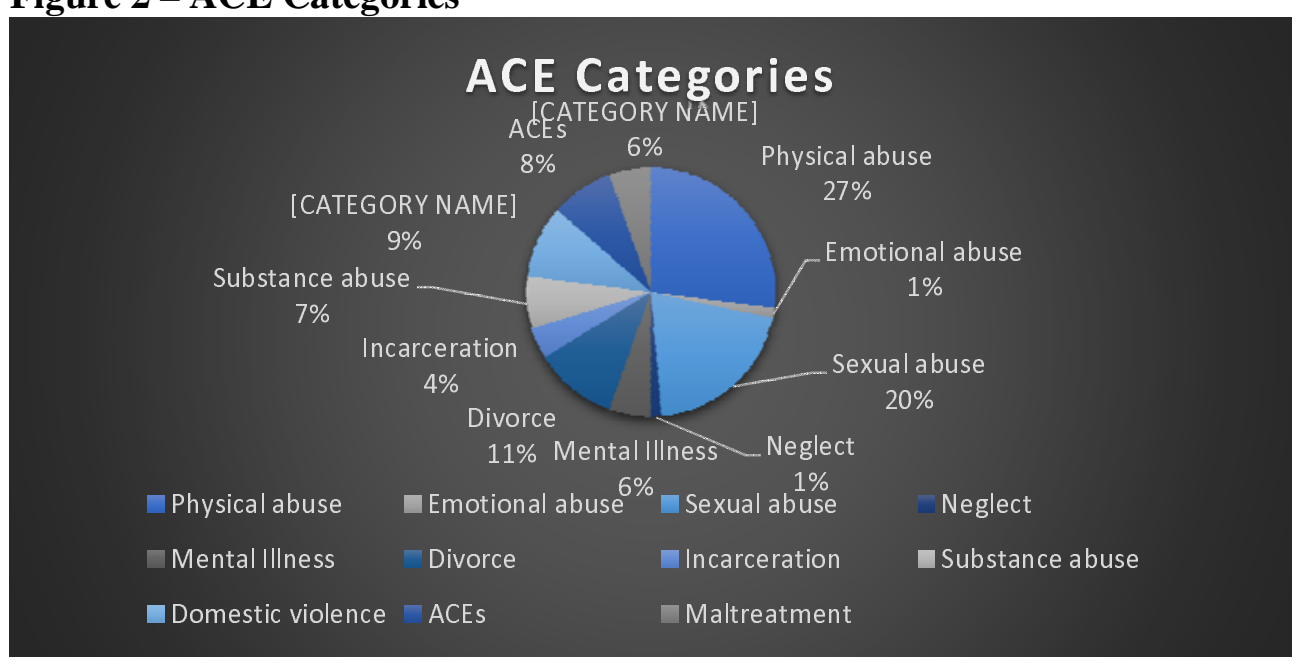

Whilst there is a growing body of literature considering siblings experiences of ACEs as a whole, most papers (92\%) have taken the approach of exploring individual ACEs rather than the collective. Of the included articles, 107 (72\%) directly focussed on siblings whereas the remaining articles explored siblings within their findings despite not being the study's main 
focus. Excluding the 37 secondary analysis articles, the most common sample population was children $(36 \% ; 53 / 148)$ followed by adults providing retrospective reports $(17 \% ; 25 / 148)$.

The analysis of articles identified three overarching themes: (1) the influence of sibling dynamics, (2) the identification of siblings, and (3) siblings who cause harm.

\section{(1) The influence of sibling dynamics:}

The influence of birth order. Exploring the role of the older sibling was a central theme within many articles. Several papers found evidence that older siblings often position themselves as carers, protecting their younger siblings from the ACE, who tend to be seen as more vulnerable (Akerlund, 2017; Callaghan et al, 2016; Foroughe \& Muller, 2014; KayeTzadok \& Davidson-Arad, 2016; Piotrowski, 2011; Ronel \& Haimoff-Ayali, 2010; Tedgard, Rastam \& Wirtberg, 2019; Vasquez \& Stensland, 2015; Woodward \& Copp, 2016). Depending on the type of adversity being experienced, the older siblings has been found to either buffer and reduce the potential impact for their younger siblings, or protect them from experiencing further abuse (Foroughe \& Muller, 2014; Piotrowski, 2011; Vasquez \& Stensland, 2015; Woodward \& Copp, 2016). Older siblings have been found to further take on the role of the parent, protecting their siblings and sometimes their parent too. Papers such as Tedgard, Rastam \& Wirtberg (2019) refer to this as parentification. Children and young people shared with Ronel \& Haimoff-Ayali (2010) that due to parental substance abuse and therefore the absence of anyone else taking care of them, older siblings saw themselves as substitutes for their parents.

While a small proportion of articles including Kaye-Tzadok \& Davidson-Arad (2016) identified that caring for younger siblings enabled older siblings to find meaning in their 
abuse, others highlight negative implications such as increased exposure for older siblings, older siblings masking their own needs and older siblings experiencing more negative impacts from the ACE (Al-Quaiz \& Raheel, 2009; Callaghan et al, 2016; Heins et al, 2011; Tailor, Stewart-Tufescu \& Piotrowski, 2015). Studies indicate that while older siblings can protect younger siblings from the impact of ACEs, this can be to their own detriment with older siblings holding the burden of responsibility (Buckley, Holt \& Whelan, 2007; Carmel, 2019; Tedgard, Rastam \& Wirtberg, 2019).

The influence of sibling relationships. Several papers have highlighted the influence sibling relationships can have when experiencing ACEs, emphasising their importance (Akerlund, 2017; Frank, 2008; Geschiere, Spijkerma \& de Glopper, 2017; Jacobs \& Sillars, 2012; Noller et al, 2008). This relationship, which for some may be the only viable ongoing relationship in the aftermath of ACEs, can either improve or worsen the impact of their experiences (Kothari et al, 2017; Piotrowski, 2011). Following surveys completed with children in Sweden, Jernbro et al (2017) identified that children experiencing physical abuse often chose to make their first disclosure to a sibling. Siblings have been found to provide an important source of support, with the absence of a sibling being associated with higher likelihood of experiencing negative effects from ACEs (Geschiere, Spijkerma \& Glopper, 2017). Sibling companionship can promote resilience, alleviate potential strains, and predict improved adjustment to the childhood adversity experienced (Jacobs \& Sillars, 2012; Vermeulen \& Greeff, 2015; Wolfe, 2016).

However, while positive sibling relationships have been found to lessen the impact of ACEs, poor sibling relationships can worsen the impact (Woodward \& Copp, 2016). Experiencing childhood adversity can also be the cause of conflict between siblings (Noller et al, 2008; 
Tucker et al, 2014; Wolfe, 2016). A case study of two brothers by McGarvey \& Haen (2005), for example, describes the siblings as having a 'traumatic bond' whereby they would re-enact their abusive experiences with each other. Further, when exploring the impact of divorce, Civitci, Civitci \& Fiyakali (2009) recognised that children and young people with a higher number of siblings can feel the need to compete with each other for their parents' attention, causing conflict within their sibling relationships. Increased conflict and poor sibling relationships have been found to increase levels of loneliness and add further stress in the aftermath of ACEs, worsening the impact (Noller et al, 2008; Wolfe, 2016).

A small number of articles have begun to consider sibling relationships with regards to whether they should be placed together having been removed from the care of their parents (Cashmore \& Parkinson, 2008; Hindle, 2007; Kothari et al, 2017). Hindle (2007) present case studies of siblings within the UK, sharing the decisions made regarding whether to be placed together with their siblings after suffering profound neglect and witnessing violence in the home. While most of these siblings had been place separately, others advocate for siblings to be placed together, arguing it to be critical for the children's sense of connection, emotional support, and continuity (Cashmore \& Parkinson, 2008; Kothari et al, 2017).

Davies (2015) is one of the few to have explicitly considered sibling relationships that are not biological, recommending that professionals considering care arrangements should not only consider biological relationships. While most of the articles included in this review either do not specify the type of sibling relationship, or imply a focus on full biological sibling relationships, a small number of articles have given consideration to others like half-siblings and stepsiblings (Gatins, Kinlaw \& Dunlap, 2014; Hollingsworth, Glass \& Heisler, 2008). Hollingsworth, Glass \& Heisler (2008) report that stepsiblings are particularly vulnerable to 
emotional abuse from parents who may draw siblings in to also cause harm. Gatins, Kinlaw \& Dunlap (2014) however found that children and young people affected by divorce appear to be better adjusted when they have half-siblings compared to those who only have full biological siblings. The number of articles explicitly exploring the different types of sibling relationships appear to be lacking when exploring ACEs.

\section{(2) The identification of siblings:}

Identifying siblings experiencing ACEs. Some articles, particularly those focussing on maltreatment or neglect, report that when one child has been identified as experiencing abuse there is an increased risk for their siblings to also experience abuse (Hamilton-Gaichritsis \& Browne, 2005; Hines, Kantor \& Holt, 2006; Lang, Cox \& Flores, 2013; MacMillan et al, 2013; Witte, Fegert \& Walper, 2018). When the childhood adversity results in fatality, surviving siblings are perceived to be at an even greater risk of harm (Damashek \& Bonner, 2010). In a retrospective study completed by Witte, Fegert \& Walper (2018), around 59\% of the 870 sibling pairs reported that both siblings had experienced maltreatment. As well as an increased risk of experiencing the abuse themselves, siblings have also been found to a be at risk of experiencing vicarious trauma from seeing the abuse of their sibling (Hollingsworth, Glass \& Heisler, 2008; Keane, Guest \& Padbury, 2013). Having a sibling in itself has also been found to be a risk indictor for ACEs, with studies finding those with multiple siblings more likely to experience adversity in their childhood (Benjet et al, 2009; Bussemakers, Kraaykam \& Tolsma, 2019). Being a twin, furthermore, has been highlighted as increasing risk, with Lindberg et al (2012) believing the increased stress of caring simultaneously for two children is a likely cause of childhood abuse. 
medRxiv preprint doi: https://doi.org/10.1101/2022.02.04.22270452; this version posted February 6, 2022. The copyright holder for this preprint (which was not certified by peer review) is the author/funder, who has granted medRxiv a license to display the preprint in perpetuity.

It is made available under a CC-BY-NC-ND 4.0 International license .

Although there is an increased likelihood of multiple siblings experiencing childhood adversity, several papers assert that the traumatic events are often experienced very differently (Boynton, Arkes \& Hoyle, 2011; Horn, Hunter \& Graham-Bermann, 2013; Skopp et al, 2005; Piotrowski, 2011; Piotrowski, Tailor \& Cormier, 2014). Even with shared traumatic experiences, children and young people can perceive it very differently and their reactions are unique (Horn, Hunter \& Grahamp-Bermann, 2013; Skopp et al, 2005). Some articles suggest that age or gender may be the cause of these different perceptions (Piotrowski, 2011; Piotrowski, Tailor \& Cormier, 2014). Morrill et al (2019) provide other possible causes, including varying exposure, individual perceptions, and unique characteristics such as emotion regulation. With a focus on parental substance abuse, Boynton, Arkes \& Hoyle (2011) found that siblings can have different memories of parental alcoholism resulting in one saying their parent was an alcoholic, when the other may not.

Implications for service provision. Given the likelihood that when one child experiences abuse siblings will too, a small number of articles have considered what this means for intervention programmes (Ahrons, 2007; Farnfield, 2017; Morrill et al, 2019; Renner \& Boel-Studt, 2017; Renner \& Driessen, 2019; Skopp et al, 2005). Some studies have argued that interventions are more meaningful when they include siblings, however in most cases only one child from a family will be referred (Ahrons, 2007; Farnfield, 2017). Recommendations have been made that service providers would be wise to assess all siblings within a family when one has experienced ACEs, and siblings should furthermore be considered when planning services, completing screenings and undertaking assessments, (Morrill et al, 2019; Renner \& Boel-Studt, 2017). Renner \& Driessen (2019) go further to believe that while siblings need increased attention from services, the needs of all family members should be assessed. Skopp et al (2005) are clear that in practice this does not simply 
medRxiv preprint doi: https://doi.org/10.1101/2022.02.04.22270452; this version posted February 6, 2022. The copyright holder for this preprint (which was not certified by peer review) is the author/funder, who has granted medRxiv a license to display the preprint in perpetuity.

It is made available under a CC-BY-NC-ND 4.0 International license .

mean referring all siblings to support programmes, as this would not be a good use of resource. Rather, individually assessing all siblings within families is much more appropriate.

\section{(3) Siblings who cause harm}

Sibling violence and abuse. Substantial consideration has also been given to siblings causing harm to other siblings, with this being the focus of nearly $40 \%$ of included articles. Several of these papers have identified abuse from a sibling as one of the most common forms of violence in the home (Finkelhor, Ormrod \& Turner, 2009; Kim \& Kim, 2019; McDonald \& Martinez, 2016; Meyers, 2014; San Kuay et al, 2016; Soler et al, 2015). Multiple papers however highlight a significant difference in the perception and understanding of this form of abuse; despite its prevalence and documented detrimental impact, sibling violence and abuse is often dismissed as normal or expected (Button \& Gealt, 2010; Desir \& Karatekin, 2018; Kim \& Kim, 2019; Phillips et al, 2018; Sporer, 2019; Tippett \& Wolke, 2015; Van Berkel, Tucker \& Finkelhor, 2018). Parents in particular have been highlighted as holding these views, being found to often minimise the frequency, severity and impact (Tucker et al, 2013). Aggression between siblings can often be seen as normative and harmless by parents (Miller et al, 2012; Van Berkel, Tucker \& Finkelhor, 2018) with some having difficulty in determining what behaviours are acceptable (McDonald \& Martinez, 2019). Tompsett, Mohoiney \& Lackey (2018) further find that children themselves can also minimise abuse and violence from a sibling.

Hoffman, Kiecolt \& Edwards (2005) and Tompsett, Mohoiney \& Lackey (2018) are in the minority, having given consideration to theoretical understandings of sibling violence and abuse. They highlight from a social learning perspective that children who experience abuse from a parent are likely to then use violence against a sibling (Hoffman, Kiecolt \& Edwards, 
2005). Aggressive parents model this behaviour as acceptable, leading to their children becoming more aggressive themselves (Thompsett, Mohoiney \& Lackey, 2018).

Sibling sexual abuse. Within the dataset of articles exploring sibling violence and abuse are a subset of papers which have explored children and young people who are sexually abused by a sibling; a crossover between the sibling violence and abuse articles and the sexual abuse articles (see figure 3). Many articles share the detrimental impact this ACE can have, finding survivors to experience anxiety, depression, and posttraumatic stress disorder, as well as being estranged from siblings or parents, and having potential future relationship or intimacy problems (Beard et al, 2013; Carlson, 2011; Falcao et al, 2014). Of significance are some of the unique implications of having a sibling cause this harm. Studies have found that it is possible for the abuse to be longer-lasting due to the accessibility of siblings, and even small age gaps between siblings can create a significant power imbalance (Carlson, Maciol \& Schneider, 2006; Tener \& Silberstein, 2019). Tener \& Silberstein (2019) further highlight that for many, this abuse only ends when the siblings leaves the family home.

\section{Figure 3 - Venn Diagram}

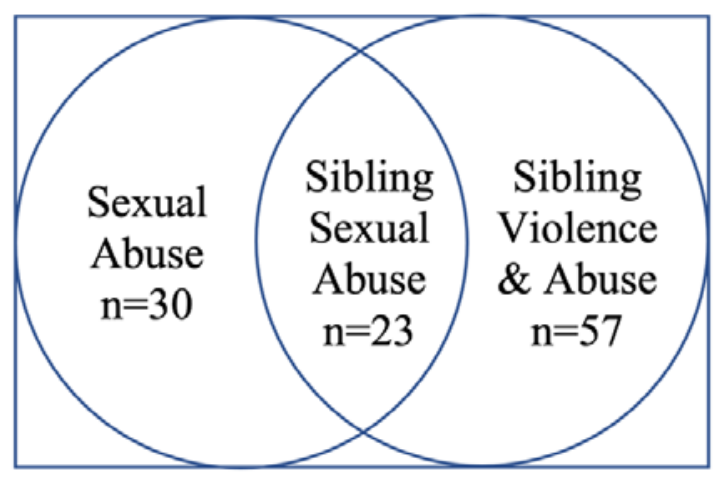

Like with other forms of sibling abuse, studies suggest that sibling sexual abuse is often normalised, most often by parents and guardians (Tarshish \& Tener, 2019; Tener et al, 2018). Some parents have been found to see these behaviours as harmless, perceiving it as a form of age-appropriate curiosity; others are believed to minimise it or deny due to shame (Tarshish 
medRxiv preprint doi: https://doi.org/10.1101/2022.02.04.22270452; this version posted February 6, 2022. The copyright holder for this preprint

\& Tener, 2019; Tener et al, 2018; Tener et al, 2019). Bass et al (2006), for example, present two contrasting case studies of families where there has been sibling incest; one of the families found the behaviour as normal whereas the other did not. Although there is a high prevalence of sibling sexual abuse, this ACE has been found to be rarely reported (Carlson, Maciol \& Schneider, 2006; Celbis, Ozcan \& Ozdemir, 2006; Joyal, Carpentier \& Martin, 2016; Katz \& Hamama, 2017). Some articles have argued this to be due parental perceptions normalising the behaviour, or not recognising the serious nature of the abuse, while others have found parents to respond to disclosures with disbelief (Krienert \& Walsh, 2011; McDonald \& Martinez, 2017; Morrill, 2014).

This underreporting has been argued to have hindered large-scale research in this area (Krienert \& Walsh, 2011). One of the difficulties associated with researching sibling sexual abuse is the lack of a universally accepted definition and understanding (Caffaro \& ConnCaffaro, 2005). Beard et al (2013), for example, define this abuse as any form of sexual behaviour among relatives in their own study. Bass et al (2006 p.93) in comparison defines it as "sexual behavior between siblings that results in feelings of anger, sadness, or fear in the child who did not initiate the behavior"; implying that some sexual behaviour would not be considered abusive. These different understandings means that those included in the sample population can vary significantly, potentially affecting the findings of studies.

\section{Discussion:}

This scoping review has provided detailed insight into what is currently known about the experiences of siblings when living with ACEs. The PAGER framework (Bradbury-Jones et $a l, 2021)$ has been utilised within this review as a means of offering a structured approach to its analysis and reporting. Five main patterns have been identified within this review which 
medRxiv preprint doi: https://doi.org/10.1101/2022.02.04.22270452; this version posted February 6, 2022. The copyright holder for this preprint (which was not certified by peer review) is the author/funder, who has granted medRxiv a license to display the preprint in perpetuity. It is made available under a CC-BY-NC-ND 4.0 International license.

will now structure the discussion, where advances and gaps will be presented along with evidence for practice and research recommendations. A full overview of this framework is provided in Table 


\begin{tabular}{|c|c|c|c|c|}
\hline Patterns & Advances & Gaps & Evidence for Practice & $\begin{array}{c}\text { Research } \\
\text { Recommendations }\end{array}$ \\
\hline $\begin{array}{l}\text { The influence of } \\
\text { birth order }\end{array}$ & $\begin{array}{l}\text { There is evidence of older } \\
\text { siblings protecting younger } \\
\text { siblings from the impact of } \\
\text { ACEs }\end{array}$ & $\begin{array}{l}\text { There is the need for ongoing } \\
\text { empirical work exploring the } \\
\text { potential increased impact on older } \\
\text { siblings who are shielding younger } \\
\text { siblings from the ACE }\end{array}$ & $\begin{array}{l}\text { It is important that support services } \\
\text { consider their response to older siblings } \\
\text { who may take far more burden than their } \\
\text { younger siblings }\end{array}$ & $\begin{array}{l}\text { To expand research exploring } \\
\text { the potential increased impact } \\
\text { on older siblings who are } \\
\text { shielding younger siblings } \\
\text { from the ACE }\end{array}$ \\
\hline $\begin{array}{l}\text { The influence of } \\
\text { sibling } \\
\text { relationships }\end{array}$ & $\begin{array}{l}\text { Understanding is growing } \\
\text { around how a positive sibling } \\
\text { relationship can reduce the } \\
\text { impact of ACEs }\end{array}$ & $\begin{array}{l}\text { Little consideration has been given to } \\
\text { the different types of siblings (full, } \\
\text { step, half), and whether this } \\
\text { influences the impact of ACEs }\end{array}$ & $\begin{array}{l}\text { It is important for statutory bodies to } \\
\text { consider the positive benefit of sibling } \\
\text { bonds, especially when making decisions } \\
\text { around whether to place siblings together } \\
\text { when removed from the care of their } \\
\text { parents. }\end{array}$ & $\begin{array}{l}\text { Far greater attention needs to } \\
\text { be given to research exploring } \\
\text { different sibling relationships } \\
\text { (full, half, step) }\end{array}$ \\
\hline $\begin{array}{l}\text { Identifying } \\
\text { siblings } \\
\text { experiencing } \\
\text { ACEs }\end{array}$ & $\begin{array}{l}\text { There is some evidence that } \\
\text { when one sibling experiences } \\
\text { ACEs, it is likely that other } \\
\text { siblings are also experiencing it }\end{array}$ & $\begin{array}{l}\text { There is limited evidence about how } \\
\text { agencies identify whether other } \\
\text { siblings have also experienced the } \\
\text { ACE }\end{array}$ & $\begin{array}{l}\text { It is important to consider all siblings } \\
\text { when one has presented with } \\
\text { experiencing childhood adversity. } \\
\text { Siblings need to be included in screening } \\
\text { and referrals into interventions }\end{array}$ & $\begin{array}{l}\text { Research is needed that } \\
\text { explores how agencies identify } \\
\text { whether other siblings have } \\
\text { also experienced ACEs }\end{array}$ \\
\hline $\begin{array}{l}\text { Siblings who } \\
\text { cause the harm }\end{array}$ & $\begin{array}{l}\text { Substantial consideration has } \\
\text { been given to siblings harming } \\
\text { other siblings. } \\
\text { The abusive behaviour is often } \\
\text { normalised and minimised when } \\
\text { it is a sibling causing the harm }\end{array}$ & $\begin{array}{l}\text { Focus tends to be on parents } \\
\text { minimising the abuse, with little } \\
\text { consideration being given to the } \\
\text { views and responses of practitioners } \\
\text { and services }\end{array}$ & $\begin{array}{l}\text { It is important that support services } \\
\text { consider their response to sibling abuse, } \\
\text { especially when the physical abuse can } \\
\text { be bi-directional. }\end{array}$ & $\begin{array}{l}\text { Need more research which } \\
\text { considers the views and } \\
\text { responses of practitioners and } \\
\text { services to children and young } \\
\text { people causing harm to siblings }\end{array}$ \\
\hline $\begin{array}{l}\text { Focus on } \\
\text { individual ACEs }\end{array}$ & $\begin{array}{l}\text { There is a growing body of } \\
\text { literature considering siblings } \\
\text { experiencing ACEs. } \\
\text { Most explore individual ACEs } \\
\text { rather than the collective. }\end{array}$ & $\begin{array}{l}\text { Some ACEs are explored } \\
\text { substantially more than others. } \\
\text { More than half do not offer any } \\
\text { theoretical understanding. }\end{array}$ & $\begin{array}{l}\text { More evidence will emerge from future } \\
\text { research considering theory }\end{array}$ & $\begin{array}{l}\text { Studies are required that } \\
\text { explore the ACEs currently } \\
\text { given less attention. } \\
\text { Theoretical understanding is } \\
\text { vital within this area of } \\
\text { research }\end{array}$ \\
\hline
\end{tabular}


(1) The influence of birth order

A clear advance identified within this review has been the overwhelming evidence of older siblings being a protective factor for their younger siblings, shielding them from adverse experiences. Described by Tedgard, Rastam \& Wirtberg (2019) as parentification, their buffering role also finds them taking on the role of the parent. Whilst there has been lot of recognition for the vulnerabilities of younger siblings, substantially less thought has been given to older siblings. Further consideration is now needed around how this protective role impacts the older sibling. This knowledge will be of significance to frontline support services who need to consider their response to older siblings who may take far more burden than their younger siblings.

\section{(1) The influence of sibling relationships}

One of the gaps evident from this scoping review is the lack of research exploring sibling types outside of biological siblings. Whilst there is a wealth of evidence around both the positive and negative influence sibling relationships can have, this has primarily been done from the sole perspective of biological siblings. Very few studies have explored step-, halfand adoptive-siblings; the majority either do not specify the type of sibling relationship, or imply a focus on full biological sibling relationships. The findings of Gatins, Kinlaw \& Dunlap (2014) that divorce appear affect those with half-siblings differently to those who only have full biological siblings, indicate that this is an area that also needs more consideration. Further research needs to be undertaken which explores the wide range of sibling relationships within society in order to understand if this influences the impact of ACEs. It will be important for statutory bodies to consider these findings in practice, especially when making decisions around whether to place siblings together when removed from the care of their parents. 
(2) Identifying siblings experiencing ACEs

Patterns and gaps have also been identified within this review relating to the identification of siblings experiencing ACEs. There is growing evidence that when one sibling experiences adversity, it is likely that their other siblings are also experiencing it, or be at risk of experiencing vicarious trauma. Lindberg et al (2012) identified twins in particular as being at increased risk of experiencing childhood abuse. Studies recommend the assessment of all siblings within a family when one has experienced childhood adversity, while remaining clear that this does not simply mean referring all siblings to support programmes, as this would not be a good use of resource (Morrill et al, 2019; Renner \& Boel-Studt, 2017; Skopp et al, 2005). Knowledge of how agencies approach the identification of siblings, however, is lacking meaning further targeted research on around this is required.

(3) Siblings who cause the harm

Substantial advances have been made in the exploration of siblings harming other siblings. An overwhelming pattern across the studies is how this abusive behaviour is often normalised and minimised, especially by parents. Considerable underreporting has been highlighted as hindering research in this area (Krienert \& Walsh, 2011), with little consideration being given to the views and responses of practitioners and frontline services. Tippett \& Wolke (2015) recognise the unique nature of this childhood adversity in that the abusive behaviour can be bi-directional, meaning the response of support services is of importance. With the current research focussing more on the views of parents, further research is needed which considers the views and responses of practitioners and services to children and young people causing harm to siblings. 
(4) Focus on individual ACEs

Whilst some advances are being made in terms of research exploring ACEs as a collective, the majority have explored them in isolation. This has resulted in some types of childhood adversity, such as physical abuse and sexual abuse, being explored to a greater degree. Research exploring some of the less studied ACEs, or ACEs as a collective, is required to develop current understanding. Children and young people who experience one form of childhood adversity are likely to experience multiple, meaning exploring ACEs as a collective would be appropriate.

\section{Limitations}

Limitations of this review include the need to reduce the timeframe in which we included articles. Whilst we had planned to include articles from 1995-2019 to capture all articles published since the first ACEs study was conducted, this timescale was reduced by 10 years due to not having the resource available to review the high volume of articles, meaning the final agreed timescale was 2005-2019 and a further 84 articles were excluded at this stage. The current study was also limited to empirical articles published in peer-reviewed journals, but we recognise that there may be additional knowledge outside of this that was not available through our search mechanisms.

\section{Conclusion}

This scoping review has examined what is currently known about the experiences of siblings living with ACEs. Included articles have highlighted overwhelming evidence of older siblings shielding younger siblings, and the likelihood that when one sibling experiences adversity, other sibling will be experiencing it themselves or vicariously. The implications of this in practice are that support services and statutory bodies need to ensure considerations 
are being made for all siblings when one has presented with experiencing childhood aversity, especially older siblings who make take far more burden. Given that more than half of the included articles did not offer any theoretical understanding, this area is of significant importance for future research. Far greater attention is also needed for research exploring different types of sibling relationships (full, step, half), and whether they influence the impact of ACEs have on children and young people. 


\section{$\underline{\text { References: }}$}

Ahrons C. (2007). Family ties after divorce: long-term implications for children. Fam Process. 46(1), 53-65. doi: 10.1111/j.1545-5300.2006.00191.x.

Akerlund, N. (2017). Caring or Vulnerable Children? Sibling Relationships When Exposed to Intimate Partner Violence. Children \& Society. 31(6), 475-485.

Al-Quaiz, A., Raheel, H. (2009). Correlates of sexual violence among adolescent females in Riyadh, Saudi Arabia. Saudi Med J, 30(6), 829-834.

Anda, R., Felitti, V., Bremner, J., Walker, J., Whitfield, C., Perry, B., Dube, S., Giles, W. (2006). The enduring effects of abuse and related adverse experiences in childhood. A convergence of evidence from neurobiology and epidemiology. European archives of psychiatry and clinical neuroscience, 256(3), 174-186. https://doi.org/10.1007/s00406-0050624-4

Arksey, H., O’Malley, L. (2005). Scoping studies: Towards a methodological framework. International Journal of Social Research Methodology, 8(1), 19-32.

Baglivio, M., Epps, N. (2016). The Interrelatedness of Adverse Childhood Experiences Among High-Risk Juvenile Offenders. Youth Violence and Juvenile Justice. 14 (3), 179-198.

Bass, L., Taylor, B., Knudson-Martin, C., Huenergardt, D. (2006). Making Sense of Abuse: Case Studies in Sibling Incest. Contemporary Family Therapy. 28(1), 87-109.

Beard, K., O’Keefe, S., Swindell, S., Stroebel, S., Griffee, K., Young, D., Linz, T. (2013). Brother-brother Incest: Data from an Anonymous Computerized Survey. Sexual Addiction \& Compulsivity.20(3), 217-253.

Benjet, C., Borges, G., Medina-Mora, M., Zambrano, J., Cruz, C., Méndez, E. (2009). Descriptive epidemiology of chronic childhood adversity in Mexican adolescents. Journal of Adolescent Health, 45(5), 483-489.

Blum, R., Li, M., Naranjo-Rivera, G. (2019) Among Young Adolescents Globally: Relationships With Depressive Symptoms and Violence Perpetration. Journal of Adolescent Health, 65(1), 86-93. https://doi.org/10.1016/j.jadohealth.2019.01.020

Boynton, M., Arkes, J., Hoyle, R. (2011). Brief report of a test of differential alcohol risk using sibling attributions of paternal alcoholism. Journal of studies on alcohol and drugs, 72(6), 1037-1040. https://doi.org/10.15288/jsad.2011.72.1037

Bradbury-Jones, C., Aveyard, H., Herber, O., Isham, L., Taylor, J., O’Malley, L. (2021). Scoping reviews: the PAGER framework for improving the quality of reporting. International Journal of Social Research Methodology.

Bramlett, M., Radel, L. (2014). Adverse family experiences among children in nonparental care, 2011-2012. Natl Health Stat Report. (74) 1-8. 
Brown, D., Anda, R., Tiemeier, H., Edwards, V., Croft, J., Giles, W. (2009). Adverse Childhood Experiences and the Risk of Premature Mortality. American Journal of Preventative Medicine. 37(5), 389-396.

Buckley, H., Holt, S., Whelan, S. (2007). Listen to Me! Children's experiences of domestic violence. Child Abuse Review. 16(5), 296-310.

Buist, K., Deković, M., Prinzie, P. (2013). Sibling relationship quality and psychopathology of children and adolescents: A meta-analysis. Clinical Psychology Review, 33, 97-106. Doi:0.1016/j.cpr.2012.10.007

Bussemakers, C., Kraaykamp, G., Tolsma, J. (2019). Co-occurance of adverse childhood experiences and its association with family characteristics. A latent class analysis with Dutch population data. Child Abuse \& Neglect. 98,

Button, D., Gealt, R. (2010). High Risk Behaviors Among Victims of Sibling Vioelnce. Jounral of Family Violence. 25, 131-140.

Caffaro, J., Conn-Caffaro, A. (2005). Treating sibling abuse families. Aggression and violent behavior, 10(5), 604-623.

Callaghan, J., Alexander, J., Sixsmith, J., Fellin, L. (2016). Children's experiences of domestic violence and abuse: siblings' accounts of relational coping. Clinical child psychology and psychiatry, 21(4), 649-668

Carlson, B. (2011). Sibling Incest: Adjustment in Adult Women Survivors. Journal of Contemporary Social Services. 92(1), 77-83.

Carlson, B., Maciol, K., Schneider, J. (2006). Sibling Incest: Reports from Forty-One Survivors. Journal of Child Sexual Abuse. 15(4), 19034.

Carmel, Y. (2019). The Experience of "Nothingness" Among Children Exposed to Interparental Violence. Journal of Loss and Trauma. 24(5-6), 473-494.

Cashmore, J., Parkinson, P. (2008). Children's and Parents' Perceptions on Children's Participation in Decision Making After Parental Separation and Divorce. Family Court Review, 46(1), 91-104.

Celbis, O., Ozcan, E., Ozdemir, B. (2006). Paternal and sibling incest: A case report. Jounral of Clinical Forensic Medicine. 13(1), 37-40.

Chapman, D., Whitfield, C., Felitti, V., Dube, S., Edwards, V., Anda, R.. (2004) Adverse childhood experiences and the risk of depressive disorders in adulthood. J Affect Disord. 82(2). 217-25. Doi: 10.1016/j.jad.2003.12.013.

Choi, J. K., Wang, D., \& Jackson, A. P. (2019). Adverse experiences in early childhood and their longitudinal impact on later behavioral problems of children living in poverty. Child Abuse and Neglect, 98(August), 104181. https://doi.org/10.1016/j.chiabu.2019.104181 
Civitci, N., Civitci, A., Fiyakali, N. (2009). Loneliness and Life Satisfaction in Adolescents with Divorced and Non-Divorced Parents. Educational Sciences: Theory and Practice, 9(2), 513-525.

Crouch, E., Probst, J. C., Radcliff, E., Bennett, K. J., \& McKinney, S. H. (2019). Prevalence of adverse childhood experiences (ACEs) among US children. Child Abuse and Neglect, 92(January), 209-218. https://doi.org/10.1016/j.chiabu.2019.04.010

Damashek, A., Bonner, B. (2010). Factors Related to Sibling Removal after a Child Maltreatment Fatality. Child Abuse \& Neglect. 34(8), 563-569.

Davies, H. (2015). Shared Parenting or Shared Care? Learning from Children's Experiences of a Post-Divorce Shared Care Arrangement. Children \& Society. 29(1), 1-14.

Desir, M., Karatekin, C. (2018) Parental reactions to parent- and sibling-directed aggression within a domestic violence context. Clin Child Psychol Psychiatry. 23(3), 457-470. doi: $10.1177 / 1359104518755219$

Dube, S., Felitti, V., Dong, M., Chapman, D., Giles, W., Anda, R. (2003) Childhood abuse, neglect, and household dysfunction and the risk of illicit drug use: the adverse childhood experiences study. Pediatrics. 111(3), 564-72. Doi: 10.1542/peds.111.3.564.

Duke, N., Pettingell, S., McMorris, B., Borowsky, I. (2010). Adolescent violence perpetration: associations with multiple types of adverse childhood experiences. Pediatrics. $125(4), 778-86$.

Edwards, R., Hadfield, L., Lucey, H., Mauthner, M. (2006). Sibling Identity and Relationships: Sisters and Brothers. Routledge: London.

Exley, R. (2021). Understanding Sibling Relationships in the Context of Gender Diversity.

Falcão, V., Jardim, P., Dinis-Oliveira, R., Magalhães, T. (2014). Forensic evaluation in alleged sibling incest against children. J Child Sex Abus. 23(7), 755-67. doi: 10.1080/10538712.2014.949394.

Farnfield S. (2017). Fix my child: The importance of including siblings in clinical assessments. Clin Child Psychol Psychiatry. 22(3), 421-435. doi: $10.1177 / 1359104517707995$.

Felitti, V., Anda, R., Nordenberg, D., Williamson, D., Spitz, A., Edwards, V., Koss, M., Marks, J. (1998). Relationship of Childhood Abuse and Household Dysfunction to Many of the Leading Causes of Death in Adults: The Adverse Childhood Experiences (ACE)Study. American Journal of Preventive Medicine, 14(4)), 774-786.

Finkelhor, D. (2020). Trends in Adverse Childhood Experiences (ACEs) in the United States. Child Abuse and Neglect. 108.

Finkelhor, D., Ormrod, R., Turner, H. (2009). The developmental epidemiology of childhood victimization. Journal of interpersonal violence, 24(5), 711-731. 
Foroughe, M., Muller, R. (2014). Attachment-Based Intervention Strategies in Family Therapy with Survivors of Intro-Familial Trauma: A Case Study. Journal of Family Violence. 29, 539-548.

Frank, H. (2008). The Influence of Divorce on the Relationship Between Adult Parent-Child and Adult Sibling Relationships. Journal of Divorce \& Remarriage. 48, 21-32.

Garner, A. (2013). Home visiting and the biology of toxic stress: Opportunities to address early childhood adversity. Pediatrics, 132(2), 65-S73.

Gatins, D., Kinlaw, C., Dunlap, L. (2014). Impact of postdivorce sibling structure on adolescent adjustment to divorce. Journal of Divorce \& Remarriage, 55(3), 239-251.

Geschiere, M., Spijkerman, R., de Glopper, A. (2017). Risk of Psychosocial Problems in Children Whose Parents Receive Outpatients Substance Abuse Treatment. International Journal of Child, Youth and Family Studies. 8(2), 11-36.

Gilligan, M., Stocker, C., Conger, K. (2020). Sibling Relationships in Adulthood: Research Findings and New Frontiers. Journal of Family Theory \& Review. 12, 305-320.

Hamilton-Giachritsis, C., Browne, K. (2005). A retrospective study of risk to siblings in abusing families. Journal of Family Psychology, 19(4), 619.

Hargreaves, M. B., Verbitsky-Savitz, N., Coffee-Borden, B., Perreras, L., White, C. R., Pecora, P. J., ... Adams, K. (2017). Advancing the measurement of collective community capacity to address adverse childhood experiences and resilience. Children and Youth Services Review, 76, 142-153. https://doi.org/10.1016/j.childyouth.2017.02.021

Heins, M., Simons, C., Lataster, T., Pfeifer, S., Versmissen, D., Lardinois, M., Marcelis, M., Delespaul, P., Krabbendam, L., van Os, J., Myin-Germeys, I. (2011). Childhood trauma and psychosis: a case-control and case-sibling comparison across different levels of genetic liability, psychopathology, and type of trauma. Am J Psychiatry. 168(12), 1286-94.

Hindle, D. (2007). Clinical Research: a psychotherapeutic assessment model for siblings in care. Journal of Child Psychotherapy. 33(1), 70-93.

Hines, D., Kantor, G., Holt, M. (2006). Similarities in siblings' experiences of neglectful parenting behaviors. Child abuse \& neglect, 30(6), 619-637.

Hoffman, K., Kiecolt, K., Edwards, J. (2005). Physical violence between siblings a theoretical and empirical analysis. Journal of Family issues, 26(8), 1103-1130.

Hollingsworth, J., Glass, J., Heisler, K. (2008). Empathy deficits in siblings of severely scapegoated children: A conceptual model. Journal of Emotional Abuse, 7(4), 69-88.

Horn, S., Hunter, E., Graham-Bermann, S. (2013). Differences and similarities in pairs of siblings exposed to intimate partner violence: A clinical case study. Partner Abuse, 4(2), 274286. 
Hughes, M., Tucker, W. (2018). Poverty as an Adverse Childhood Experience. North Carolina Medical Journal. 79(2), 124-126.

Jacobs, K., Sillars, A. (2012). Sibling Support During Post-Divorce Adjustment: An Idiographic Analysis of Support Forms, Functions, and Relationship Types. Jounral of Family Communication. 12, 167-187.

Jernbro, C., Otterman, G., Lucas, S., Tindberg, Y., Janson, S. (2017). Disclosure of Child Physical Abuse and Perceived Adult Support among Swedish Adolescents. Child Abuse Review, (6), 451-464. https://doi.org/10.1002/car.2443

Joyal, C., Carpentier, J., Martin, C. (2016). Discriminant factors for adolescent sexual offending: On the usefulness of considering both victim age and sibling incest. Child Abuse Negl. 54, 10-22. doi: 10.1016/j.chiabu.2016.01.006.

Katz, C., Hamama, L. (2017). From My Own Brother in My Own Home: Children's Experiences and Perceptions Following Alleged Sibling Incest. J Interpers Violence. 32(23), 3648-3668. doi: 10.1177/0886260515600876

Kaye-Tzadok, A., Davidson-Arad, B. (2016). Posttraumatic growth among women survivors of childhood sexual abuse: Its relation to cognitive strategies, posttraumatic symptoms, and resilience. Psychol Trauma. 8(5), 550-558. Doi: 10.1037/tra0000103.

Keane, M., Guest, A., Padbury, J. (2013). A Balancing Act: A Family Perspective to Sibling Sexual Abuse. Child Abuse Review. 22(4), 246-254.

Kim, J., Kim, E. (2016). Bullied by Siblings and Peers: The Role of Rejecting/Neglecting Parenting and Friendship Quality Among Korean Children. J Interpers Violence. 34(11), 2203-2226. doi: 10.1177/0886260516659659.

Kiselica, M., Morrill-Richards, M. (2007). Sibling maltreatment: the forgotten abuse. Journal of Counselling \& Development, 85, 148-161.

Kothari, B., McBeath, B., Sorenson, P., Bank, L., Waid, J., Webb, S., Steele, J. (2017) An intervention to improve sibling relationship quality among youth in foster care: Results of a randomized clinical trial. Child Abuse Negl. 63, 19-29. Doi: 10.1016/j.chiabu.2016.11.010.

Krienert, J., Walsh, J. (2011). Sibling sexual abuse: An empirical analysis of offender, victim, and event characteristics in National Incident-Based Reporting System (NIBRS) data, 20002007. Journal of Child Sexual Abuse: Research, Treatment, \& Program Innovations for Victims, Survivors, \& Offenders, $\quad$ 20(4), 353372. https://doi.org/10.1080/10538712.2011.588190

Lang, C., Cox, M., Flores, G. (2013). Maltreatment in multiple-birth children. Child abuse \& neglect, 37(12), 1109-1113.

Leban, L., \& Gibson, C. L. (2019). The role of gender in the relationship between adverse childhood experiences and delinquency and substance use in adolescence. Journal of Criminal Justice, 66(August 2019), 101637. https://doi.org/10.1016/j.jcrimjus.2019.101637 
Lindberg, D., Shapiro, R., Laskey, A., Pallin, D., Blood, E., Berger, R., ExSTRA Investigators. (2012). Prevalence of abusive injuries in siblings and household contacts of physically abused children. Pediatrics, 130(2), 193-201.

Lo, HPW., Lau, VWY., Yu, ESM. (2017). Clinical Characteristics and Developmental Profile of Child Abuse Victims Assessed at Child Assessment Service in Hong Kong: A Five-year Retrospective Study. HK J Paediatr. 22, 88-96.

MacMillan, H., Tanaka, M., Duku, E., Vaillancourt, T., Boyle, M. (2013). Child physical and sexual abuse in a community sample of young adults: results from the Ontario Child Health Study. Child Abuse Negl. 37(1), 14-21. Doi: 10.1016/j.chiabu.2012.06.005.

Manyema, M., \& Richter, L. M. (2019). Adverse childhood experiences: prevalence and associated factors among South African young adults. Heliyon, 5(12), e03003. https://doi.org/10.1016/j.heliyon.2019.e03003

McDonald, C., Martinez, K. (2017). Victims' retrospective explanations of sibling sexual violence. Journal of child sexual abuse, 26(7), 874-888.

McDonald, C., Martinez, K. (2019). Victim narratives of sibling emotional abuse. Child Welfare, 97(2), 1-21.

McGarvey, T., Haen, C. (2005). Intervention Strategies for Treating Traumatized Siblings on a Pediatric Inpatient Unit. American Journal of Orthopsychiatry. 75(3), 395-408.

Meyers, A. (2014). A call to child welfare: Protect children from sibling abuse. Qualitative Social Work. 13(5), 654-670.

Milevksy, A. (2011). Sibling relationships in childhood and adolescence: Predictors and outcomes. Columbia University Press: New York.

Miller, L., Grabell, A., Thomas, A., Bermann, E., Graham-Bermann, S. (2012). The associations between community violence, television violence, intimate partner violence, parent-child aggression, and aggression in sibling relationships of a sample of preschoolers. Psychology of Violence, 2, 165-178.

Moher, D., Liberati, A., Tetzlaff, J., \& Altman, D. G., \& The PRISMA Group. (2009). Preferred Reporting Items for Systematic Reviews and Meta-analyses: The PRISMA statement. PloS Medicine, 6(7).

Morrill, M. (2014). Sibling sexual abuse: An exploratory study of long-term consequences for self-esteem and counseling considerations. Journal of family violence, 29(2), 205-213.

Morrill, M., Schulz, M., Nevarez, M., Preacher, K., Waldinger, R. (2019). Assessing withinand between-family variations in an expanded measure of childhood adversity. Psychological assessment, 31(5), 660 .

Noller, P., Feeney, J., Sheehan, G., Darlington, Y., Rogers, C. (2008). Conflict in Divorcing and Continuously Married Families: A Study of Marital, Parent-Child and Sibling Relationships. Journal of Divorce and Marriage. 28(1-2), 1-24. 
Peters, M. D. J., Godfrey, C. M., Khalil, H., McInerney, P., Parker, D., \& Soares, C. B. (2015). Guidance for conducting systematic scoping reviews. International Journal of Evidence-Based Healthcare. 13 (1), 141-146.

Phillips, D., Bowie, B., Wan, D., Yukevich, K. (2018). Sibling Violence and Children Hospitalized for Serious Mental and Behavioral Health Problems. Journal of Interpersonal Violence. 33(16), 2258-2578.

Piotrowski, C. (2011) Patterns of adjustment among siblings exposed to intimate partner violence. J Fam Psychol. 25(1), 19-28. doi: 10.1037/a0022428.

Piotrowski, C., Tailor, K., Cormier, D. (2014). Siblings exposed to intimate partner violence: Linking sibling relationship quality \& child adjustment problems. Child abuse \& neglect, 38(1), 123-134.

Renner, L., Boel-Studt, S. (2017). Physical family violence and externalizing and internalizing behaviors among children and adolescents. American journal of orthopsychiatry, 87(4), 474.

Renner, L., Driessen, M. (2019). Siblings who are exposed to child maltreatment: Practices reported by county children's services supervisors. Journal of Public Child Welfare. 13(5), 491-511.

Ronel, N., Haimoff-Ayali, R. (2010). Risk and resilience: the family experience of adolescents with an addicted parent. Int J Offender Ther Comp Criminol. 54(3), 448-72. doi: $10.1177 / 0306624 X 09332314$.

San Kuay, H., Lee, S., Centifanti, L., Parnis, A., Mrozik, J., Tiffin, P. (2016). Adolescents as perpetrators of aggression within the family. International journal of law and psychiatry, 47, 60-67.

Shonkoff, J., Boyce, T., McEwen, B. (2009). Neuroscience, Molecular Biology, and Childhood Roots of Health Disparities: Building a New Framework for Health Promotion and Disease Prevention. 301(21), 2252-2259.

Shonkoff, J., Garner, A., Siegel, B., Dobbins, M., Earls, M., McGuinn, L., Pascoe, J., Wood, D. (2012) The lifelong effects of early childhood adversity and toxic stress. Pediatrics, $129,232-246$.

Skopp, N., McDonald, R., Manke, B., Jouriles, E. (2005). Siblings in domestically violent families: experiences of interparent conflict and adjustment problems. Journal of Family Psychology, 19(2), 324.

Soler, L., Forns, M., Kirchner, T., Segura, A. (2015). Relationship between particular areas of victimization and mental health in the context of multiple victimizations in Spanish adolescents. Eur Child Adolesc Psychiatry. 24(4), 417-425. doi: 10.1007/s00787-014-05912.

Sporer, K. (2019). Aggressive children with mental illness: A conceptual model of familylevel outcomes. Journal of interpersonal violence, 34(3), 447-474. 
Tailor, K., Stewart-Tufescu, A., Piotrowski, C. (2015). Children exposed to intimate partner violence: Influences of parenting, family distress, and siblings. Journal of Family Psychology, 29(1), 29-38. https://doi.org/10.1037/a0038584

Tarshish, N., Tener, D. (2019) Exemption committees as an alternative to legal procedure in cases of sibling sexual abuse: The approaches of Israeli CAC professionals. Child Abuse Negl. doi: 10.1016/j.chiabu.2019.104088

Tedgård, E., Råstam, M., Wirtberg, I. (2019) An upbringing with substance-abusing parents: Experiences of parentification and dysfunctional communication. Nordisk Alkohol Nark. 36(3), 223-247. doi: 10.1177/1455072518814308.

Tener, D., Lusky, E., Tarshish, N., Turjeman, S. (2018). Parental attitudes following disclosure of sibling sexual abuse: A child advocacy center intervention study. American Journal of Orthopsychiatry, 88(6), 661.

Tener, D., Newman, A., Yates, P., Tarshish. (2019). Child Advocacy Center Intervention with Sibling Sexual abuse Cases: Cross-cultural comparison of professionals' perspectives and experiences. Child Abuse \& Neglect. 105,

Tener, D., Silberstein, M. (2019). Therapeutic interventions with child survivors of sibling sexual abuse: The professionals' perspective. Child Abuse Negl. 89, 192-202. doi: 10.1016/j.chiabu.2019.01.010.

Tippett, N., Wolke, D (2015). Aggression between siblings: Associations with the home environment and peer bullying. Aggress Behav. 41(1), 14-24. doi: 10.1002/ab.21557.

Tompsett, C., Mahoney, A., Lackey, J. (2018). Sibling aggression among clinic-referred children and adolescents. Journal of Clinical Child \& Adolescent Psychology, 47(6), 941953.

Tricco, A. C., Lillie, E., Zarin, W., O’Brien, K. K., Colquhoun, H., Levac, D., Moher, D., Peters, M. D., Horsley, T., Weeks, L., \& Hempel, S. (2018). PRISMA extension for scoping reviews (PRISMAScR): Checklist and explanation. Annals of Internal Medicine, 169, 467473

Tucker, C., Finkelhor, D., Turner, H., Shattuck, A. (2013). Association of sibling aggression with child and adolescent mental health. Pediatrics, 132(1), 79-84.

Tucker, C., Finkelhor, D., Turner, H., Shattuck, A. (2014). Sibling and peer victimization in childhood and adolescence. Child Abuse \& Neglect. 38(10), 1599-1606.

van Berkel, S., Tucker, C., Finkelhor, D. (2018). The Combination of Sibling Victimization and Parental Child Maltreatment on Mental Health Problems and Delinquency. Child Maltreat. 23(3), 244-253. doi: 10.1177/1077559517751670.

Vasquez, M., Stensland, M. (2015). Adopted Children with Reactive Attachment Disorder: A Qualitative Study on Family Processes. Clin Soc Work J. 44, 319-332. 
Vermeulen, T., Greeff, A. (2015). Family Resilience Resources in Coping with Child Sexual Abuse in South Africa. Journal of Child Sexual Abuse. 24(5), 555-571.

Witte, S., Fegert, J., Walper, S.. (2018). Risk of maltreatment for siblings: Factors associated with similar and different childhood experiences in a dyadic sample of adult siblings. Child Abuse Negl. 76, 321-333. doi: 10.1016/j.chiabu.2017.11.009.

Wolfe, J. (2016). The effects of maternal alcohol use disorders on childhood relationships and mental health. Soc Psychiatry Psychiatr Epidemiol. 51, 1439-1448

Woodward, T., Copp, J. (2016). Maternal incarceration and children's delinquent involvement: The role of sibling relationships. Children and Youth Services Review. 70, 340348.

Yucel, D., Yuan A. (2015). Do siblings matter? The effect of siblings on socio-emotional development and educational aspirations among early adolescents. Child Indicators Research, 8, 671-697. 